\title{
Partisipasi Masyarakat Lokal Terhadap Wisata Edukasi Di Green School Bali, Abiansemal, Badung
}

Andra Muslimina,1, I Nyoman Sukma Arida.a,2

1andralim@mail.com, ${ }^{2}$ sukma_arida@unud.ac.id

a Program Studi S1 Destinasi Pariwisata, Fakultas Pariwisata,Universitas Udayana, Jl. Dr. R. Goris, Denpasar, Bali 80232 Indonesia

\section{Abstract}

This study was conducted with the aim of identifying the form of local community participation in educational tourism implemented by Green School Bali, Abiansemal, Badung. The data collection methods that used were observation, in-depth interview, literature study and documentation. The data analysis techniques that used are qualitative data analysis. The form of local community participation in the implementation of Green School Bali educational tour is categorized in vertical participation because the role of local communities in this educational tour is located as a subordinate or worker status. This happens because the tour that held in Green School Bali is a non profit-based, the income obtained by the tour will be fully allocated to the scholarship students in Green School Bali.

Keywords: Community Based Tourism, Educational Tourism

\section{PENDAHULUAN}

Green School Bali adalah sekolah privat internasional yang berlokasi di Kecamatan Abiansemal, Kabupaten Badung, Provinsi Bali, Indonesia. Sekolah ini didirikan oleh John dan Cyntia Hardy pada tahun 2006 setelah keluar dari bisnis perhiasanya yang kemudian dikelola oleh yayasan Kul Kul dengan tujuan mendidik keberlanjutan melalui pembelajaran yang terpadu, kewirausahaan dan lingkungan sekolah tanpa dinding. Pendekatan holistik dan memberdayakan siswa-siswi untuk menjadi pemimpin hijau. John dan Cyntia Hardy merupakan suami-istri berkewarganegaraan Kanada yang kini menetap di Bali.

Sekolah internasional ini membuka kelas mulai dari Preschool setara dengan pendidikan anak usia dini hingga High School yang setara dengan sekolah menengah atas. Sekolah ini mempunyai ciri khas dan keunikan tersendiri yang terlihat pada seluruh material bangunan sekolah terbuat dari bahan ramah lingkungan dan bisa didaur ulang lagi seperti kaca mobil bekas, bambu, jerami dan lumpur khusus sebagai penganti semen demi menjaga keberlangsungan lingkungan.

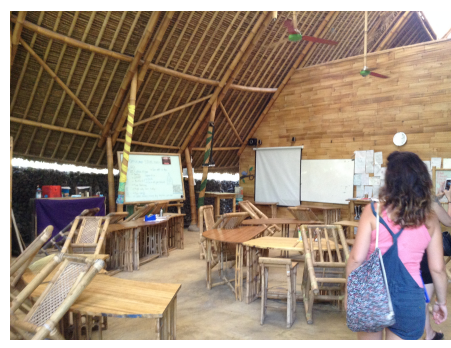

Gambar 1.1 Ruang Kelas di Green School Bali Sumber: Hasil Penelitian,2017
Keunikan ekologi dan konsep keberlanjutan sekolah ini mampu menarik banyak perhatian masyarakat, sehingga dibuka wisata edukasi science atau ilmu pengetahuan yang berbentuk dalam sebuah tur. Merupakan jenis aktivitas pariwisata dilakukan oleh wisatawan pada umumnya mengambil liburan satu hari yang melakukan perjalanan dengan tujuan pembelajaran dan pendidikan yang berbasis pada IPTEK (Ilmu Pengentahuan dan Teknologi) sebagai tujuan utama maupun tujuan kedua. Wisata edukasi dibuka untuk untuk umum mengakomodir wisatawan dengan minat khusus yang ingin belajar langsung dan observasi di Green School Bali yang terkenal dengan desain ekologi berkelanjutan serta fokus terhadap pendidikan. Memberi percontohan hidup yang ramah lingkungan merupakah tujuan dari wisata edukasi yang diadakan di Green School Bali.

Green School Bali membuka wisata edukasi ini karena adanya kecendrungan masyarakat global, regional dan nasional untuk (back to nature) kembali ke alam (Sukma Arida, 2009). Kegiatan utama dari wisata edukasi yang dilaksanakan merupakan tur dengan melakuan observasi terhadap atraksi wisata yang ditawarkan yaitu berjalan kaki mengelilingi seluruh bagian sekolah dengan bantuan pemandu tur, objek atraksi yang dikunjungi umumnya adalah fasilitas belajar siswa seperti lapangan sekolah, ruang istirahat, ruang kelas, green camp, 'kembali' recycling, ruang pertemuan, panel surya, microhydro vortex, kolam renang alami, jembatan millenium, kebun, peternakan dan jantung sekolah. Pendapatan dari wisata edukasi sepenuhnya 
akan dialokasikan untuk membantu biaya sekolah siswa pemegang beasiswa di Green School Bali.

Green School Bali membuka wisata edukasi dengan konsep keberkelanjutanya mampu mengatasi permasalahn sampah lingkungan dan juga mempunyai perspektif ekologis, keberlanjutan budaya lokal ditekankan, hal ini berkaitan dengan upaya mempertahankan peningalan budaya serta arsitektural tradisional di tur wisata edukasi, pembangunan dan pengembangan telah menunjukkan dukunganya pada pembangunan berskala mikro serta berbasis masyarakat. Dalam hal ini maysarakat lokal bekerja dalam Yayasan Kul-Kul ikut membangun dan berpartisipasi dalam menjaga keberlangsungan wisata edukasi dalam pariwisata berkelanjutan yang dilaksanakan oleh Green School Bali. Data karyawan dalam wisata edukasi di Green School Bali disajikan dalam Tabel berikut:

Gambar 1.2 Komposisi Karyawan

Pengelola Wisata Edukasi di Green School Bali

Menurut Asal Daerah

\begin{tabular}{|c|c|c|}
\hline Jabatan & Jumlah & Penduduk Asal \\
\hline \multirow{2}{*}{$\begin{array}{l}\text { Petugas } \\
\text { Keamanan }\end{array}$} & 5 & Abiansemal \\
\hline & 1 & Singapadu \\
\hline \multirow{2}{*}{$\begin{array}{l}\text { Reservasi } \\
\text { dan } \\
\text { Reception }\end{array}$} & 1 & Jakarta \\
\hline & 2 & Abiansemal \\
\hline \multirow{4}{*}{$\begin{array}{l}\text { Pemandu } \\
\text { Wisata }\end{array}$} & 3 & WNA \\
\hline & 1 & Jakarta \\
\hline & 4 & Abiansemal \\
\hline & 1 & Semarang \\
\hline $\begin{array}{l}\text { Penyedia } \\
\text { Makanan } \\
\text { dan } \\
\text { Minuman }\end{array}$ & 2 & Abiansemal \\
\hline \multirow{2}{*}{$\begin{array}{l}\text { Sales dan } \\
\text { Marketing }\end{array}$} & 1 & Jakarta \\
\hline & 1 & Abiansemal \\
\hline IT & 1 & Surabaya \\
\hline
\end{tabular}

Sumber: Hasil Penelitian,

Tabel 1.1 menunjukan bahwa karyawan didominasi oleh warga lokal Abiansemal dengan presentase sebanyak $61 \%$ dari total 23 karyawan yang terdiri dari petugas keamanan, reservasi dan reception, pemandu wisata serta penyedia makan dan minuman. Dengan presentase warga lokal yang tinggi maka wisata edukasi ini bisa dikategorikan wisata edukasi berbasis masyarakat lokal.

Pembangunan pariwisata berkelanjutan berdasarkan Yaman dan Mohd (2004) ditandai dengan beberapa kondisi diantaranya adalah: 1) dalam proses perencanaan dan pembangunan pariwisata terdapat partisipasi anggota masyarakat, 2) pendidikan bagi pengunjung atau wisatawan dan tuan rumah atau pelaku industri, 3) kualitas habitat flora dan fauna, penggunaan energi serta iklim mikro harus diterima dan didukung, 4) adanya investasi dan pengembangan terhadap transportasi alternatif.

Salah satu keberhasilan pariwisata keberlanjutan (sustainable tourism) adalah adanya pengaruh partisipasi anggota masyarakat dalam setiap proses perencanaan dan pembangunan, dalam hal ini adalah tur yang diadakan di Green School Bali, sebagaimana telah dijekaskan oleh Yaman dan Mohd (2004). Berdasarkan uraian tersebut maka tujuan dari penelitian ini adalah untuk mengetahui bentuk partisipasi atau pelibatan masyarakat lokal dalam wisata edukasi yang diselenggarakan oleh Green School Bali.

\section{TINJAUAN PUSTAKA}

\section{1 Konsep Partisipasi Masyarakat dalam Pengembangan Pariwisata Berbasis Masyarakat}

Menurut (Oxford Advanced Learner's Dictionary) dalam bahasa inggris kata Partisipasi diartikan sebagai "taking part of doing an action in an activity or event", yang artinya merupakan suatu tindakan berupa keikut sertaan dalam suatu aktivitas atau kegiatan acara. Menurut Tasci dkk (2013) partisipasi masyarakat adalah salah satu karakteristik yang vital dari pariwisata berbasis masyarakat.

Suansri (2003) mendefinisikan CBT (Community Based Tourism) adalah kegiatan pariwisata dengan menghormati aspek keberlanjutan lingkungan, sosial dan budaya. CBT merupakan salah satu media untuk membangun dan mewujudkan pembangunan pariwisata yang berkelanjutan.

Bentuk partisipasi masyarakat akan dilihat dengan mengaitkan 10 Prinsip dasar CBT (community based tourism) atau pariwisata berbasis masyarakat yang telah dipaparkan oleh Suansri (2003) sebagai indikator: 
1. Bentuk pengakuan, pengembangan dan dukungan wisata edukasi yang dilaksanakan Green School Bali terhadap kepemilikan komunitas masyarakat lokal.

2. Keterlibatan anggota masyarakat dalam melakukan seluruh aspek kegiatan dalam wisata edukasi Green School Bali.

3. Pengembangan kebanggaan masyarakat lokal dalam wisata edukasi yang dilaksanakan Green School Bali.

4. Perbaikan kualitas hidup masyarakat lokal dalam Green School Bali.

5. Pertanggung jawaban keberlangsungan lingkungan pada area wisata edukasi Green School Bali.

6. Bentuk proteksi pada keindahan keunikan karakter dan budaya di area wisata edukasi Green School Bali, Abiansemal.

7. Bantuan perkembangan edukasi mengenai pertukaran budaya pada wisata edukasi Green School Bali.

8. Penghargaan divergensi budaya dan martabat manusia dalam wisata edukasi Green School Bali.

9. Pembagian keuntungan secara merata pada anggota wisata edukasi Green School Bali.

10. Peran dalam penentuan pemerataan pendapatan (distribusi pendapatan) dalam setiap proyek yang ada dalam wisata edukasi di Green School Bali.

Sehingga didapat bentuk partisipasi yang terbagi dalam dua bentuk. Menurut Effendi (2002) dibagi menjadi partisipasi vertikal dan partisipasi horizontal:

1. Partisipasi Vertikal, wujud keterlibatan atau peran masyarakat dalam suatu program dalam wisata edukasi di Green School Bali, dengan mengidentifikasi hubungan masyarakat dalam posisi sebagai status klien atau bawahan.

2. Partisipasi horizontal, bentuk keterlibatan atau peran masyarakat dalam suatu program dalam wisata edukasi di Green School Bali, dengan mengidentifikasi setiap anggota masyarakat ikut serta secara horizontal satu dengan yang lainnya. Hal ini merupakan ciri awal berkembangnya masyarakat mandiri.

\section{METODE PENELITIAN}

Penelitian ini dilakukan di sebuah sekolah internasional bernama Green School Bali yang terletak di Kecamatan Abiansemal, Kabupaten Badung. Lokasi penelitian ini berjarak kurang lebih $14 \mathrm{KM}$ dari pusat kota Denpasar dengan waktu tempuh sekitar 45 menit. Lokasi ini dipilih berdasarkan fokus penelitian yang terletak di Green School Bali yang membuka tur wisata edukasi.

Teknik pengumpulan data yang digunakan dalam penelitian ini adalah observasi, wawancara mendalam, studi kepustakaan dan dokumentasi. Selanjutnya data yang terkumpul dianalisis menggunakan teknik deskriptif kualitatif yang merupakan gambaran dari data yang disusun sistematis, aktual, dan akurat mengenai fakta-fakta yang ada, Moleong (2011).

Pemilihan informan sebagai sumber data dalam penelitian ini berdasarkan pada asas subyek yang mengetahui permasalahan, memiliki data dan bersedia memberikan informasi lengkap dan akurat. Informan yang bertindak sebagai sumber data harus memenuhi syarat, informan atau narasumber (key informan) dalam penelitian ini adalah manajemen wisata edukasi yang dilaksanakan di Green School Bali, masyarakat lokal yang bekerja dalam wisata edukasi di Green School Bali dan masyarakat lokal daerah Green School Bali.

\section{HASIL DAN PEMBAHASAN}

\subsection{Partisipasi Masyarakat terhadap Wisata Edukasi Green School Bali}

Bentuk keterlibatan masyarakat lokal dijabarkan melalui sepuluh prinsip dasar CBT (community based tourism) atau pariwisata berbasis masyarakat menurut Suansri (2003).

1. Bentuk pengakuan, pengembangan dan dukungan wisata edukasi yang dilaksanakan Green School Bali terhadap kepemilikan komunitas masyarakat lokal

Gerry Pranaputra selaku wisata edukasi Marketing Associate di Green School Bali, penyelengara wisata edukasi yaitu Green School Bali mengakui sepenuhnya adanya masyarakat atau komunitas lokal yang berpartisipasi aktif dalam aktivitas tur wisata edukasi di Green School Bali. Masyarakat lokal terlibat aktif hampir dalam seluruh aspek kegiatan wisata edukasi dan menjalankan peranya dengan baik, 
diantaranya adalah sebagai petugas check-in, petugas keamanan, pemandu tur serta penyedia makanan dan minuman.

2. Keterlibatan anggota masyarakat dalam melakukan seluruh aspek kegiatan dalam wisata edukasi Green School Bali

Tur wisata edukasi di Green School Bali dikelola oleh suatu divisi khusus yang anggotanya didominasi oleh masyarakat lokal di area Abiansemal, Bali. Pekerja di Green School Bali yang didominasi komunitas lokal menjalankan peranya dalam beberapa bidang pekerjaan dalam wisata edukasi diantaranya adalah sebagai petugas keamanan, petugas check-in, penyedia makanan dan minuman dan beberapa merupakan pemandu tur.

3. Pengembangan kebanggaan masyarakat lokal dalam wisata edukasi yang dilaksanakan Green School Bali.

Dapat bekerja dan belajar di Green School Bali merupakan salah satu kebanggan. Brand dan konsep pembelajaran di sekolah ini sangat bagus karena konsep utama sekolah adalah mendorong seluruh komunitas belajar (siswa, pengajar dan staff) bisa bersahabat dan menghargai alam. Sekolah memanfaatkan energi alternatif dengan menggunakan microhydro vortex dan panel surya.

Bentuk bangunan sekolah sangat unik dengan ciri khas seluruh material bangunanya dapat didaur ulang dan ramah lingkungan seperti bambu dan jerami sehingga membuat Green School Bali terkenal keseluruh mancanegara. Masyarakat lokal yang bekerja untuk wisata edukasi di Green School Bali secara tidak langsung juga dididik untuk menerapakn pola hidup hijau.

4. Perbaikan kualitas hidup masyarakat lokal dalam Green School Bali.

Pengembangan dan perbaikan kualitas hidup bagi komunitas lokal yang bekerja untuk wisata edukasi di Green School Bali merupakan sangat baik tidak dilihat hanya dalam bentuk materi yang diperoleh melainkan pengetahuan dan ilmu yang didapatkan, khususnya dalam bidang pelestarian lingkungan hidup serta sosial. Masyarakat lokal awal bekerja untuk wisata edukasi di Green School Bali menjalankan pelatihan khusus sesuai dengan fungsi pekerjaan agar bisa menjalankan peranya dengan sangat baik dengan ukuran standarisasi yang tinggi guna membangun dan mempertahankan brand sekolah yang baik.
5. Pertanggung jawaban keberlangsungan lingkungan pada area wisata edukasi Green School Bali.

Jaminan keberlangsungan lingkungan area Green School Bali terjamin dan baik, dikarenakan keberlangsungan lingkungan searah dengan tujuan dan konsep wisata edukasi yang diselenggarakan di Green School Bali. Peserta wisata edukasi dibatasi tidak boleh lebih dari 30 peserta dalam satu hari dengan alasan menghindari kerusakan ekologi yang diakibatkan oleh pariwisata massal. Makanan dan minuman yang disajikan untuk peserta wisata edukasi menggunakan bahan perkebunan yang herbal. Sampah yang dihasilkan oleh kegiatan wisata edukasi didaur ulang atau dimanfaatkan kembali sehingga mengurangi kerusakan alam.

6. Bentuk proteksi pada keindahan keunikan karakter dan budaya di area wisata edukasi Green School Bali, Abiansemal.

Bentuk proteksi pada keunikan karakter dan budaya dalam wisata edukasi di Green School Bali terlihat pada material bangunan yang digunakan pada seluruh bangunan sekolah yaitu bambu, batu dan jerami, pertahanan pada budaya terlihat pada pelestarian tari-tarian bali yang dipelajari oleh siswa dan siswi yang mayoritas bukan berkewarganegaraan Indonesia. Siswa dan siswi aktif terlibat dalam beberapa kegiatan kegamaan di Bali seperti mengarak 'Ogoh-ogoh' pada malam sebelum nyepi.

7. Bantuan perkembangan edukasi mengenai pertukaran budaya pada wisata edukasi Green School Bali.

Pertukaran budaya dalam wisata edukasi di Green School Bali terjadi dalam berbagai aspek meskipun tidak terlihat adanya dominasi suatu budaya. Peserta wisata edukasi di Green School Bali didominasi oleh wisatawan mancanegara dengan budaya yang beragam berinteraksi secara langsung dengan penyelenggara wisata edukasi (pekerja masyarakat lokal) dengan sangat baik.

8. Penghargaan divergensi budaya dan martabat manusia dalam wisata edukasi Green School Bali.

Seluruh top manajemen dan masyarakat lokal penyelenggara wisata edukasi di Green School Bali menghargai adanya perbedaan 
budaya dan martabat manusia. Setiap orang diperlakukan baik, sama dan adil.

9. Pembagian keuntungan secara merata pada anggota wisata edukasi Green School Bali.

Distribusi keuntungan wisata edukasi di Green School Bali yang didapat tidak bisa dibagi rata kepada seluruh anggota penyelenggara tur dalam hal ini masyarakat lokal. Keuntungan yang dihasilkan sepenuhnya disalurkan untuk mensuport anggaran sekolah siswa dan siswi pemegang beasiswa di Green School Bali. Manajemen tur tidak memperoleh keuntungan sama sekali dari penjualan tiket wisata edukasi, pendapatan penyelenggara tur yang didapat hanya bersumber melalui gaji.

10. Peran dalam penentuan pemerataan pendapatan (distribusi pendapatan) dalam setiap proyek yang ada dalam wisata edukasi di Green School Bali.

Pendapatan yang diperoleh wisata edukasi di Green School Bali sepenuhnya disumbangkan untuk siswa dan siswi pemegang beasiswa di Green Schoool Bali. Anggota pelaksana tur dalam hal ini adalah masyarakat lokal tidak bisa menentukan prosentase pendapatan dalam proyek. Kegiatan wisata edukasi ini tidak berorientasi bisnis atau tidak untuk meraup keuntungan, kegiatan wisata edukasi ini berorientasi non-profit atau tidak bertujuan untuk mencari keuntungan.

\subsection{Bentuk Partisipasi Masyarakat}

Setelah mengaitkan 10 prinsip dasar $C B T$ (community based tourism) atau pariwisata berbasis masyarakat menurut Suansri (2003), kemudian didapat hasil identifikasi bentuk partisipasi menurut Effendi (2002) yang dibagi dalam bentuk partisipasi vertikal dan partisipasi horizontal. Partisipasi masyarakat dalam wisata edukasi di Green School Bali dikategorikan dalam bentuk partisipasi vertikal. Karena bentuk peran komunitas lokal atau keterlibatan dalam wisata edukasi di Green School Bali ini adalah sebagai status pekerja, bawahan, pengikut atau klien.

\subsection{Dinamika Partisispasi Masyarakat}

Gren School Bali di tahun 2016 mengadakan perluasan bisnis atau ekspansi dengan menciptakan dan mengembangkan komplek perumahan yang diberi nama Green Village Bali. Green Village Bali adalah komunitas terencana berupa akomodasi yang meliputi rumah-rumah, restoran dan spa dikembangkan oleh Green School Bali. Green Village Bali berdiri di sempadan Sungai Ayung, kawasan ini meliputi 18 rumah yang dirancang khusus oleh tim 'Ibuku', mempunyai karakteristik bambu dan jerami seperti di Green School Bali sebagai material bangunan utama. Setiap rumah di Green Village Bali mempunyai desain yang unik sehingga mempunyai bentuk yang berbeda dari setiap rumah.

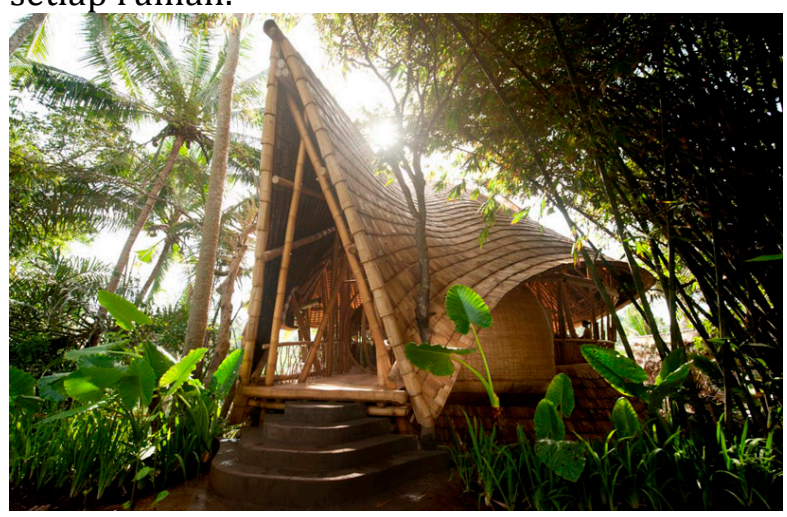

Gambar 1.3 Sunrinse House di Green Village Bali Sumber: greenvillagebali.com, 2016

Perluasan usaha yang dikembangkan oleh Green School Bali berupa pembangunan Green Village Bali ini menimbulkan kecemasan pada komunitas lokal Abiansemal, Badung. Abiansemal merupakan satu diantara Desa Adat yang ada di Bali, mempunyai karakteristik komunitas adat yang menghargai nilai tata krama, pergaulan dan sosial berdasarkan ajaran agama Hindu Bali.

Berdasarkan hasil wawancara dengan mantan kepala banjar Sibang Gede yang bernama Anak Agung Raka, menyatakan bahwa awal kemunculan Green School Bali di Abiansemal, Sekolah memisahkan diri dari komunitas lokal melalu keterlibatan pasif pada kegiatan masyarakat lokal. Bentuk tanggung jawab perusahaan atau CSR (Corporate Social Responsibility) Green School Bali terhadap komunitas lokal Abiansemal kurang dirasakan baik pada awal keberadaanya, karena tidak adanya aktivitas atau program yang bersifat sosial dan menguntungkan untuk masyarakat luas, khususnya Abiansemal.

Meskipun pada saat ini Green School Bali telah melaksanakan CSR (Corporate Social Responsibility) melalui bertanggaung jawab sepenuhnya terhadap pengembangan kapasitas SDM (Sumber Daya Manusia) di lingkungan masyarakat, pengembangan ekonomi 
masyarakat kawasan wilayah kerja Green School Bali, pemeliharaan relasional antara Green School Bali dan masyarakat lokal lingkungan Abiansemal, pelestarian dan pemberdayaan lingkungan meliputi fisik, sosial dan budaya.

Berdasarkan pada awal keberadaan Green School Bali, sekolah menjadi komunitas ekslusif dengan memisahkan diri dari masyarakat atau komunitas lokal. Kekhawatiran dan kecemasan masyarakat timbul karena ekspansi bisnis yang dilaksanakan oleh Green School Bali dengan membuka Green Village Bali, karena masyarakat khawatir Green Village Bali mengikuti Green School Bali menjadi komunitas ekslusif yang membatasi diri dari komunitas lokal pada awal keberadaanya.

\section{SIMPULAN DAN SARAN}

\subsection{Simpulan}

Berdasarkan penjabaran dan indentifikasi maka didapat hasil bentuk partisipasi atau keikutsertaan masyarakat dalam wisata edukasi di Green School Bali dikategorikan dalam partisipasi berbentuk vertikal, karena peran atau keikutsertaan masyarakat dalam wisata edukasi di Green School ini terletak sebagai pekerja atau bawahan.

Kegiatan wisata edukasi ini tidak berorientasi bisnis atau untuk meraup keuntungan. Kegiatan wisata edukasi di Green School Bali ini berorientasi non-profit atau tidak bertujuan untuk mencari keuntungan. Keuntungan yang dihasilkan sepenuhnya disalurkan untuk mensuport anggaran sekolah siswa dan siswi pemegang beasiswa di Green School Bali. Manajemen tidak memperoleh keuntungan dari pendapatn wisata edukasi, pendapatan penyelenggara tur (dalam hal ini adalah masyarakat lokal) yang didapat hanya berasal dari gaji yang sebelumnya telah disepakati.

\subsection{Saran}

Berdasarkan hasil penelitian terdapat beberapa hal yang perlu mendapat perhatian dari pihak terkait yaitu:

a) Memaksimalkan keikutsertaan komunitas atau masyarakat lokal di dalam aktivitas atau program yang diselenggarakan wisata edukasi Green School Bali, supaya manfaat dan keuntungan yang dihasilkan juga mampu mensejahtrakan komunitas atau masyarakat lokal Desa Adat Abiansemal.

b) Bagi penelitian selanjutnya yang masih minim mengenai pariwisata berbasis masyarakat, di dalam wisata edukasi. Dibutuhkan penelitian lanjutan terkait beberapa hal yang perlu ditambahkan serta diperhatikan dalam suatu wisata edukasi.

\section{Daftar Pustaka:}

Arida, I Nyoman Sukma. 2009. Meretas Jalan Ekowisata Bali. Denpasar: Udayana University Press.

Effendi, I. 2002. Analisa Presepsi Masyarakat terhadap Taman Nasional Gunung Lauser, Desa Harapan Jaya, Kabupaten Langat, Sumatera Utara. Medan : Universitas Sumatera Utara.

Moleong, Lexy j. 2007. Metodologi Penelitian Kualitatif. Bandung: Remaja Rosda Karya.

Suansri, Potjana. 2003. Community Based Tourism Handbook. Thailand : Rest Project.

Yaman, Amat Ramsa dan A, Mohd. 2004. "Communitybased Ecotourism: New Proposition for Sustainable Development and Environment Conservation in Malaysia," dalam Journal of Applied Sciences volume IV (4). Malaysia: Asian Network for Scientific Information.

www.greenschool.org di akses tanggal 10 Mei 2016 pukul 10:00 wita. 